\title{
Perspectivas de la sustentabilidad: teoría y campos de análisis
}

\author{
Prospects for sustainability: theory and areas of analysis \\ Róger Martínez Castillo Daniel Martínez Chaves² \\ Recibido: 26/8/2015 / Aprobado: 12/4/2016
}

\begin{abstract}
Resumen
El desarrollo convencional lleva hacia una crisis general, por el uso y abuso de los ecosistemas y generación de problemas sociales, debido a su estilo de vida mercado-céntrico. Por lo tanto, la sociedad debe replantear las relaciones humanas mismas y estas con la biosfera, de ahí la importancia del gran desafío y esfuerzos de conservación. Es necesaria la caracterización del proceso requerido, para lo cual se enfatiza que no es lo mismo sostenible que sustentable. La sustentabilidad se refiere a la capacidad del sistema para mantener su productividad estable a pesar de las perturbaciones económicas y naturales, externas o internas. El desarrollo sustentable se fundamenta en principios éticos, como el respeto al proceso de regeneración de los ciclos naturales, valores políticos, como la democracia participativa y equidad social, y normas de comportamiento y conductas morales, como la racionalidad ambiental. El desarrollo sustentable es descentralizado y autogestionario, capaz de satisfacer las necesidades básicas de la población, respetar la diversidad cultural y mejorar la calidad de vida, sin degradar el ciclo natural.
\end{abstract}

Palabras claves: desarrollo, sociedad, naturaleza, biodiversidad y sustentabilidad.

\section{Abstract}

Conventional development is pushing society towards a general crisis due to the [ab] uses of natural ecosystems and social problems based on market-centered ways of living. Therefore, society must rethink its relationship with humanity and with the biosphere. The importance of the big challenge ahead and the efforts to guarantee environmental conservation is based on that correlation. It is important to characterize the required process in which the concept supportable should refer to truly sustainable. Sustainability refers to the system's potential to maintain its productivity goals stable in spite of economic and environmental disturbances, both internal and external. Sustainable development is based on ethical principles, such as a genuine respect for natural regeneration cycles and political values as well as on participatory democracy, social equity, moralistic behaviors, and environmental rationality. Sustainable development must be decentralized and self-managed. It must be able to satisfy basic social needs, respect cultural diversity and look for ways to improve quality of life, avoiding natural cycle degradation.

Keywords: development, society, nature, biodiversity, sustainability.

${ }^{1}$ Doctor en Agroecologia. Master en Educacion Ambiental. Catedrático SP-UCR. Coordinador de la Carrera de Turismo Ecológico, Universidad de Costa Rica, Sede del Pacifico. Correo electrónico: roger.martinez@ucr.ac.cr.

${ }^{2}$ Magister en Gestión Hotelera. Consultor de marketing turístico científico del management. Presidente de Agnes Tourism. Correo electrónico: 14.daniel.88@gmail.com 


\section{Introducción}

La presente investigación pretende abordar el tema de la sustentabilidad dentro del marco de los modelos de desarrollo, los cuales aspectos sociales, económicos, ambientales, entre otros. Se comprende este tema en la interacción compleja de las sociedades con la biosfera, sus formas de producción a partir de esta y en una búsqueda, a través de la investigación y el conocimiento, de cómo reducir los impactos negativos en el uso de los recursos ambientales.

Se pretende abordar un planteamiento teóricometodológico y epistemológico, el cual permita al lector una comprensión integral acerca de los fundamentos críticos y creativos de la investigación en torno a la sustentabilidad, expuestos brevemente de la siguiente forma:

- Enfoque teórico: conceptualización y caracterización de la sustentabilidad.

- Enfoque metodológico: método de estudio y sus aplicaciones para el diagnóstico y análisis de los modelos de desarrollo, a partir de perspectivas multidimensionales (dimensiones de la sustentabilidad), con el fin de identificar elementos que impiden la sustentabilidad.

- Enfoque epistemológico: estructuración del conocimiento, mediante la investigación rigurosa de las manifestaciones de los fenómenos de la sustentabilidad y desmitificación del concepto "sostenible", que no representa la perspectiva teórico-práctica, sino una línea de pensamiento del paradigma convencional.

Para lograr estos aspectos, es preciso formular una línea de análisis crítica sobre la situación socioambiental y económica, y sus antecedentes (causas) que han influido, a tal magnitud, que escapa del control humano, pues obedece a una tendencia exclusivamente productivista, al mercado desregularizado, que se torna antiecológico y antisocial. La gravedad de esta situación se debe sobre todo a la irresponsabilidad e incomprensión hacia la misma sociedad y la naturaleza, manifestadas por el estilo de desarrollo (extracción, producción y consumo])del modelo liberal (de Benoist, 2013; Shamir, 2015).

El modelo liberal ha sido el vencedor y sobreviviente, militar, en el nivel ideológico y político, tanto al fascismo y nacionalsocialismo (1920-1945) y al marxismo (1917-1990), por tanto al no existir alternativas que ejerzan resistencia, se debe su comprensión integral como ideología dominante que ha llevado sus principios a todos los rincones del planeta, a través de la globalización, el mundialismo y el libre mercado, con el dominio de los medios de comunicación. Esta imposición del modelo liberal, en el plano ideológico y económico lleva a la sociedad contemporánea a vivir momentos de crisis profunda que afectan las relaciones de la población con su entorno natural, así como a la distribución y equidad social en el acceso a los recursos y bienes proporcionados por el planeta Tierra (Stern, 2007), debido a esto, las brechas sociales se maximizan, y por tanto la situación se torna insustentable.

La racionalidad del mundo industrial es intrínsecamente incompatible con los patrones y principios de la naturaleza (Toledo,1995); por eso, se está viviendo y sufriendo una grave crisis ecológica de escala global (Boff, 1996), sin un planteamiento que responda a qué se hará cuando los recursos se hayan agotado o degradado; este cuestionamiento debe ser respondido por todos los diversos actores de la sociedad moderna, entre los que se incluyen: gobiernos, corporaciones, empresas locales, universidades, organismos internacionales, cámaras de desarrollo y otros.

Entre las causas, por las cuales se entra en una crisis económica, social y ambiental se resaltan: 
$\checkmark \quad$ el papel de los seres humanos en la naturaleza ha sido y es muy destructivo;

$\checkmark$ la idea aristotélica de lo humano como centro, separado de lo natural, dicho en palabras de Dugin (2013), la ideología liberal imperante es completamente antropocéntrica, a lo que se le puede agregar que también es difusa en términos socioculturales; $y$

$\checkmark \quad$ la visión mercadocéntrica en la relación sociedad-naturaleza, es en este punto donde se demuestra una gran contradicción interna del modelo de desarrollo, aplicado en mayor medida en la industria turística, en la que, por un lado indica que la naturaleza es el principal producto, sin embargo, al mismo tiempo el método de producción y comercialización no garantiza el respeto integral de los elementos naturales, ni del respeto hacia las sociedades locales (Cañada, 2013).

El desarrollo convencional ha llevado hacia una crisis general, por el abuso de los ecosistemas y su estilo de vida (mercado-céntrico: modelo de producción orientado al consumismo desenfrenado, a través de intereses meramente economicistas, más allá de la satisfacción de necesidades sociales).

El sistema económico que domina casi todos los rincones del planeta es el capitalismo, desde una perspectiva práctica, basada en la ideología liberal propia de la modernidad, a partir del "laissez faire" de Adam Smith, este modelo se caracteriza por:

$\checkmark \quad$ El capitalismo es un sistema que busca expandirse continuamente, en concordancia con los procesos globalizadores mundialistas, en los que prima lo económico por encima de otros elementos (Savin, 2015; Soral, 2014), para lo cual cuenta incluso con el beneplácito de instituciones globales que pretenden liberalizar el comercio (Meyer, 2004; Cañada, 2013), el mejor ejemplo es la Organización Mundial del Comercio.

$\checkmark \quad$ La expansión conduce a inversiones en el extranjero en búsqueda de fuentes seguras de materias primas, trabajo barato, y nuevos mercados, lo cual genera pobreza tanto en los países donde aterriza, debido a la complicidad de los gobiernos locales, así como en los países de donde se fugan las empresas (Milá, 2012).

$\checkmark$ Un sistema que, por su misma naturaleza, debe crecer y expandirse eventualmente chocará con la finitud de los recursos naturales (Freytas, 2010).

$\checkmark$ Un sistema orientado hacia el crecimiento exponencial en la búsqueda de ganancias inevitablemente trascenderá los límites del planeta, ante esto surge el escenario más avanzado del capitalismo, el cual es definido por Dugin (2012b) como "el financiarismo", en el que los Estados son desplazados en la toma de decisiones por parte de las corporaciones multinacionales, lo que desemboca en una "corporatocracia" (Baquiast, 2010; Sachs, 2012). Esto se logra en complicidad de actores locales como bien apunta Milá (2014).

$\checkmark \quad$ El capitalismo no es únicamente un sistema económico, sino también un sistema político, ideológico, cultural, judicial y social para sostener el proceso de riqueza y acumulación, ya Polanyi (1944) lo advertía desde los años 40. Varios autores que se movilizan dentro de este marco de pensamiento intentan replantear hacia modelos más sustentables, a través de lo que se denomina como "capitalismo con consciencia", concepto que abordan algunos autores (Mackey y Sisodia, 2013), la idea en teoría es interesante, pero en la práctica no pasa de ser un oxímoron, puesto que no abandona la perspectiva mercadocéntrica.

La sociedad debe replantear su interacción e historia con su eje principal en las relaciones humanas y estas con la biosfera. El modelo de vida de la sociedad occidental, basado en la idea de que "más es mejor", es el principal causante de los desajustes entre la naturaleza y la sociedad. Cambiar las visiones y los estilos que apuntalan el actual sistema constituye un esfuerzo imprescindible para evitar el colapso (Fernández, 2009). Los problemas ecológicos nos son coyunturales sino 
estructurales, en este punto a pesar de no haber planteado elementos novedosos o creativos, los autores marxistas del siglo XX sí supieron identificar tales problemas; sin embargo su enfoque es asimismo economicista. Para salir de este problema hará falta otra gran transformación en los valores, prioridades y necesidades, desde el enfoque eterno de la Tradición de los pueblos como herramienta de resistencia frente a la modernidad y sus antivalores: atomismo, materialismo, liberalismo.

La temática ambiental es compleja porque abarca muchos aspectos de la realidad que ocurren en simultáneo y con interrelaciones no del todo comprendidas, requiere del trabajo transdisciplinario (ingenieros, biólogos, abogados, economistas, administradores, físicos, químicos, sociólogos y otros) para poder abordarla (Dunne, 2015).

Los efectos alcanzados por el desarrollo actual son ampliamente documentados: calentamiento global, destrucción de la capa de ozono, aunque haya síntomas de recuperación (PNUMA, 2014), transporte de contaminantes persistentes (Martín, 2012), degradación ambiental de ecosistemas (Dunne, 2014), pérdida de biodiversidad, desertificación de suelos (Collado, 2012), por nombrar algunos.

Los aspectos ambientales, sociales, culturales, ideológicos, demográficos, migratorios, económicos, urbanísticos, financieros, energéticos, alimentarios, inmobiliarios, globalizadores y otros del momento actual están muy entrelazados, por lo que no parece que se puedan articular soluciones sencillas basadas en parches que tapan una parte del problema, mientras agravan otros. De ahí la importancia que el gran desafío y esfuerzos de conservación se orienten hacia un nuevo modelo de desarrollo, con la generación de tecnologías alternativas. Pues actualmente, "...la naturaleza ya no puede ser pensada sin la sociedad y la sociedad ya no puede ser pensada sin la naturaleza" (Beck, 1998).

La Tabla 1 plantea un análisis comparativo del desarrollo.

\section{Tabla 1: Comparación del desarrollo convencional y desarrollo sustentable}

\begin{tabular}{|c|c|}
\hline Convencional & Sustentable \\
\hline 1-Mercado desregulado: capital privado. & 1-Mercado regulado: capital social. \\
\hline 2-Ganancia privada, individual. & 2-Ganancia social, colectiva. \\
\hline 3-Valor de cambio. & 3-Valor de uso. \\
\hline 4-Monocultivo (desarrollo externo). & 4-Policultivo (desarrollo interno). \\
\hline 5-Uso único del agroecosistema. & 5-Manejo múltiple del agroecosistema \\
\hline 6-Labranza máxima. & 6-Labranza necesaria. \\
\hline 7-Producción insustentable. & 7-Producción sustentable. \\
\hline 8-Enfoque antropo-mercadocéntrico. & 8-Enfoque eco-bio-céntrico. \\
\hline 9-La naturaleza mercantilizada. & 9-La naturaleza es respetada. \\
\hline 10-Atomística: separa las cosas. & 10-Holística: todo esta enlazado. \\
\hline 11-Desnaturaliza la sociedad. & 11-Naturaliza la sociedad. \\
\hline 12-Des-socializa la naturaleza. & 12-Socializa la naturaleza. \\
\hline 33-Recursos naturales: visión fetichista. & 13-Bienes naturales: énfasis en la vida. \\
\hline
\end{tabular}


Con base en la Tabla 1, a partir de los planteamientos de Norgaard (1996) se destaca cómo el desarrollo convencional ha estado marcado principalmente por un enfoque más economicista o mercado-céntrico, mientras que el modelo de desarrollo sustentable plantea una perspectiva más distributiva, donde la producción se realiza con consciencia ecológica como punto de partida, para minimizar los impactos ambientales y el agotamiento de los recursos, por lo que es posible desarrollar la economía como un medio, no como un fin en sí misma.

Para salir de esta situación será necesario regular los mercados, reformular la producción, la distribución y el consumo, organizar la vida de un modo más lento y cercano, cuestionar los mecanismos financieros y las reglas del comercio generadores una "deudocracia" (comprendida como el modelo de endeudamiento de un Estado contra los requerimientos de su población, en beneficio de un acreedor internacional privado, mediante ingeniería financiera que explota a una nación utilizando la práctica usuraria del interés compuesto acumulativo, por lo tanto los prestamistas privados obtienen ganancias extraordinarias, mientras la nación se empobrece y sufre de desigualdad, ya que deberá pagar tanto el monto prestado, así como sus intereses y los intereses de esos intereses) y su consecuente servidumbre del interés del dinero (Sack, 1927; Beveraggi, 1982; Bochaca, 2007; Soral, 2015); revisar críticamente y cuestionar la globalización económica y su axioma errado, que clama que "el capital genera trabajo", cuando es al revés -el trabajo genera el capital-; socializar la aplicación tecnocientífica; situar en el centro de interés la equidad entre las personas y el respeto a los Derechos Humanos (principalmente en el nivel de sus responsabilidades dentro del marco regulatorio de la totalidad de la sociedad) y ciclos naturales. Los Estados deben tomar fuerza y ser actores principales dentro de los procesos de planificación orientada hacia el desarrollo sustentable (Milá, 2014).

\section{Sobre el término "sostenibilidad" o "sustentabilidad" del desarrollo: interpretación correcta}

De igual manera se destaca la diferenciación teórica y práctica entre los términos "sostenibilidad" y "sustentabilidad", al separarlos en perspectiva comparativa en torno a los alcances, visiones y métodos de cada uno. Esta comparación surge tras el Informe sobre Nuestro Futuro Común [1987-1988] coordinado por Gro Harlem Brundtland (1988) en el marco de las Naciones Unidas, se popularizando el objetivo del "desarrollo sostenible", el cual se entiende como aquel que permite "satisfacer nuestras necesidades actuales sin comprometer la capacidad de las generaciones futuras para satisfacer las suyas". Al respecto, se exponen algunos puntos como críticas al concepto "sostenible":

$\checkmark \quad$ Este concepto proponía mantener el modelo de crecimiento económico "ajustando" los parámetros para permitir su continuidad en el tiempo, pero dejaba intacta y fuera de debate las principales bases del modelo de producción depredador que, reconocía, lleva al planeta a la debacle. Es decir, que detectaba un problema, pero no lo comprendía (relación causa-efecto).

$\checkmark \quad$ A su vez, esquivaba el debate sobre los aspectos socioeconómicos y las consecuencias de este modelo económico, como la generación creciente de la brecha entre ricos y pobres.

La aceptación generalizada del término "sostenible" en un contexto de desarrollo económico es ambivalente. Por una parte, evidencia una mayor preocupación por la salud de los ecosistemas que mantienen la vida en la Tierra, y desplazan esta preocupación hacia el campo de la gestión económica, por lo que es al final un concepto meramente economicista. Mientras, la falta de claridad con la que se maneja este término promulga que las buenas intenciones que lo informan se queden en meros gestos en el vacío, y que no contribuyan a reconvertir la sociedad industrial sobre bases más sustentables. 
El discurso sobre la sostenibilidad fue una respuesta a la escuela de los límites del crecimiento, la cual desde los años setenta del siglo XX postula la inexorable presión del crecimiento económico sobre la naturaleza. El término "desarrollo sostenible" servía para mantener en los países industrializados en el crecimiento y permite escapar de las connotaciones éticas que tal crecimiento conlleva. A pesar de que se extendía la preocupación por la "sostenibilidad" se subrayaba implícitamente, con ello, la insostenibilidad del modelo económico que ha conducido la era agroindustrial.

Mientras, el término "desarrollo sustentable" sí ha acompañado al proceso para una concientización y sensibilización ambiental de la sociedad global. En la Cumbre de la Tierra (1992), el teólogo Leonardo Boff planteaba que lo que se necesita no era un desarrollo sustentable, sino sociedades sustentables. A partir de allí, distintos sectores de la sociedad fueron apropiándose del término "sustentabilidad", como una nueva perspectiva, que fuese capaz de afrontar los retos económicos, sociales y ambientales.

El desarrollo sustentable se refiere a un constante proceso de cambio, donde la explotación de los recursos naturales, la dirección de la inversión y progreso científico- tecnológico, junto al cambio institucional, permiten compatibilizar la satisfacción de necesidades sociales presentes y futuras (Bifani, 1997). Estos elementos se indican en la Ilustración 1, donde se ejemplifica su interrelación:

\section{Ilustración 1. Características de la sustentabilidad para satisfacción de necesidades humanas}

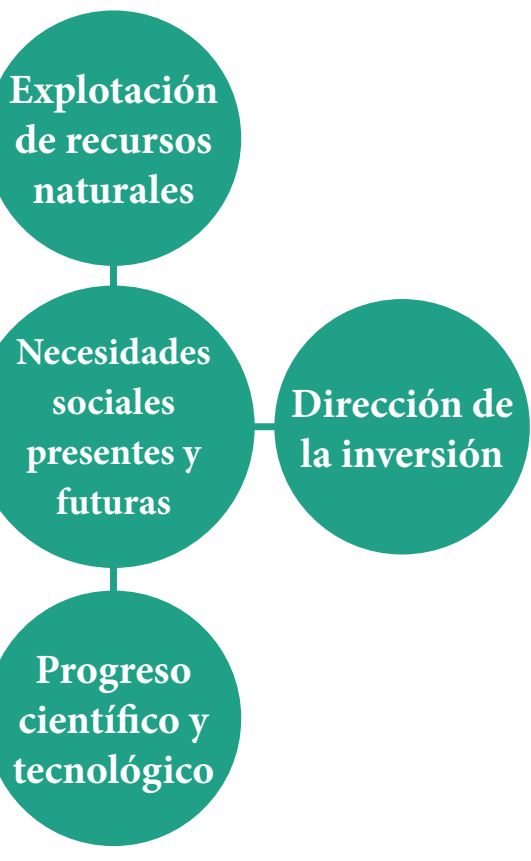

Fuente: Elaboración propia a partir de Bifani (1997).
La Cumbre Mundial sobre el Desarrollo Sostenible, realizada en Johannesburgo en 2002, marca el cierre de este ciclo al centrarse en el multilateralismo como una estrategia clave para el cumplimiento y la aplicación del desarrollo sustentable. Es así como estas cumbres han servido de plataforma para incorporar la idea del desarrollo sustentable en los planes de acción local, regional y global.
La situación actual socioeconómica y ambiental, dentro del modelo liberal, es más problemática porque esta expansión provoca un deterioro ecológico muy acentuado, con lo que la moderación y reconversión del sistema no sólo habría que aceptarlas, sino promoverla para evitar que prosiga el deterioro - provocado por el modelo liberal-. Hace falta que la sociedad reaccione al deterioro en las condiciones de habitabilidad 
de la Tierra, y corrija el funcionamiento del sistema económico que lo origina y que no piensa replantearse.

La sustentabilidad del sistema de producción se refiere a la capacidad para mantener su productividad a pesar de las perturbaciones mayores tanto económicas como naturales, externas o internas. Aquí, la sustentabilidad va en función de las características naturales del sistema y las presiones e intervenciones que sufre; así como aquellas intervenciones sociales, económicas y técnicas que se hacen para contrarrestar presiones negativas; donde se destaca la resiliencia del sistema (Bifani, 1997).

El desarrollo sustentable se ha convertido en un proyecto orientado a erradicar la pobreza y regular las riquezas, a satisfacer las necesidades básicas y a mejorar la calidad de vida de la población; pero se olvida que hay que construir paradigmas alternativos de desarrollo, acordes con las necesidades específicas de cada país o región, inclusive de cada sector social, de ahí la importancia de la soberanía nacional. Para ello, será necesario definir los procesos que orienten la construcción de una lógica sustentable, ante la globalización económica, basada en principios de economía solidaria, equidad social, diversidad cultural sin imponer unas a otras, mediante métodos de persuasión psicológica ni física, una visión de mundo único, como lo ha hecho el capitalismo (Freytas, 2011a)- y sustentabilidad ecológica. Para comprender esta lógica y su relación de elementos, visualizar Ilustración 2.

\section{Ilustración 2. Lógica sustentable}

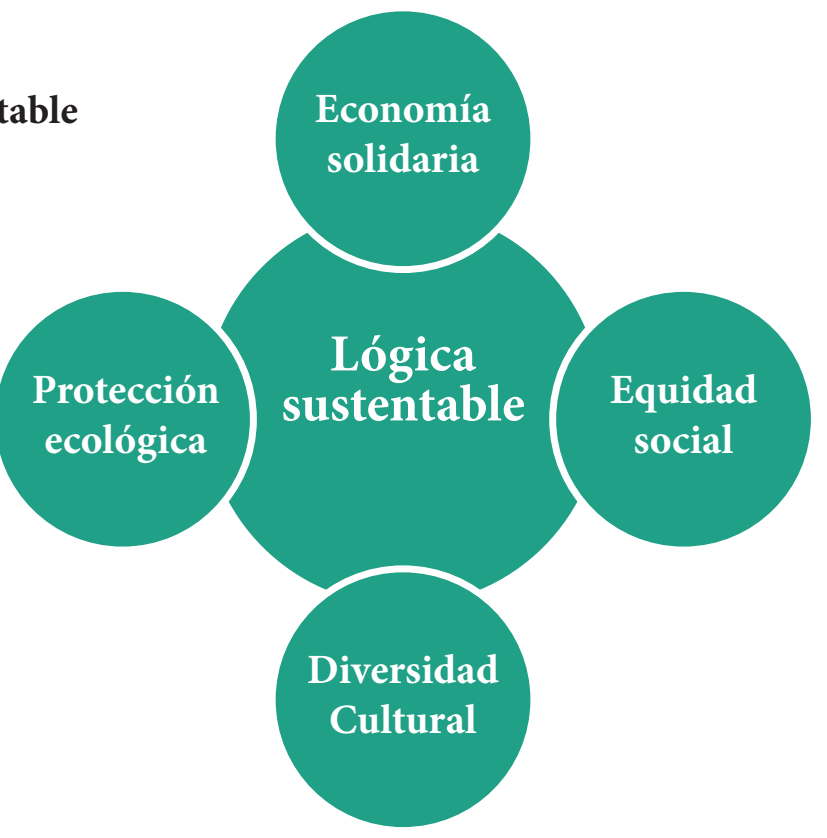

Fuente: Elaboración propia.

Ello implica nuevos principios de valoración de la naturaleza, nuevas estrategias de reapropiación de los procesos productivos y nuevos sentidos que movilicen y reorganicen la sociedad.

El Desarrollo Sustentable se fundamenta en principios éticos, como el respeto a los ciclos naturales; valores políticos, como la democracia participativa, mediante un Estado fuerte que planifique correctamente los recursos y garantice la competitividad de la industria nacional y equidad social, lo cual replantea el viejo axioma de los especuladores financieros que sugiere que "el capital genera trabajo", cuando es todo lo contrario, es el trabajo el que genera el capital, honesto, solidario y soberano; y normas de comportamiento, como racionalidad ambiental. Además, ese desarrollo es igualitario, descentralizado y autogestionario; es capaz de satisfacer las necesidades básicas de 
la población, regular los intereses corporativos, respetar la diversidad cultural y mejorar la calidad de vida (Leff, 1998).

El concepto de sustentabilidad se basa en el reconocimiento de los límites y potenciales de la naturaleza en cuanto a su manejo responsable, así como la complejidad ambiental: inspirar una nueva comprensión del mundo para enfrentar los desafíos de la humanidad. Este concepto promueve una nueva alianza naturaleza-sociedad, para fundar una nueva economía, al reorientar los potenciales de la ciencia y la tecnología, y construir una nueva cultura política fundada en una ética de la sustentabilidad -en valores tradicionales, creencias, sentimientos y saberes- la cual renueva los sentidos existenciales, los mundos de vida y las formas de habitar el planeta Tierra (Duran y Lara, 2010).

\section{Dimensiones de la Sustentabilidad}

El Informe sobre los Recursos Mundiales 1992, elaborado por el PNUD -Programa de las Naciones Unidad para el Desarrollo, por sus siglas en inglés-, enfoca el desarrollo sustentable como un proceso que requiere un progreso simultáneo global en las diversas dimensiones: económica, humana, ambiental y tecnológica. Por eso, para definir la sustentabilidad es necesario considerar todas sus dimensiones de manera articulada, al respecto, se proponen varias dimensiones:

\section{1- Dimensión ecológica o ambiental}

Esta exige que el desarrollo pueda preservar y potenciar la regeneración y complejidad de los ecosistemas, su productividad, los ciclos naturales y la biodiversidad (Martínez, 2012). Se requiere valorar la dimensión territorial de los distintos ambientes. Esta dimensión está muy ligada a la sobrevivencia física y cultural de los pueblos y sectores excluidos (Boff, 2004; Martínez 2012). Esta dimensión, desde la perspectiva sustentable, promueve la protección de los bienes o recursos naturales necesarios para la soberanía y seguridad alimentaria (IICA, 2009) y energética; a su vez, comprende el requerimiento de satisfacer a las poblaciones el acceso de justa distribución y regular los intereses particulares o "corporatocráticos".

Esta dimensión está condicionada por la provisión de bienes naturales y de servicios ambientales de un espacio geográfico. A pesar de que la abundancia de recursos naturales no garantiza el carácter endógeno del desarrollo sustentable, si constituye el potencial básico del desarrollo territorial (Durán, 2010). Es necesario incorporar la dimensión ecológica en las decisiones políticas y examinar los efectos ambientales de la apropiación/ producción y consumo de bienes naturales que cada sociedad promueve en las distintas etapas históricas y su aplicación.

La sustentabilidad ecológica se refiere a la relación con la capacidad de carga de los ecosistemas (Onaindia, 2007), es decir, a la magnitud de la naturaleza para absorber y recomponerse de las influencias antrópicas (humanas). La capacidad de carga es el número promedio de población que puede ser soportada por los recursos de un territorio y se define en relación con una población, imprescindible para la supervivencia; por encima de este límite se considera depredación, debido a que se supera la capacidad y degrada su condición. El concepto de capacidad de carga permite evaluar los límites máximos del crecimiento de la población, según diversos niveles tecnológicos (Duran y Lara, 2010).

La capacidad de carga puede tener varios significados. Los cuales se exponen en la tabla 2: 
Tabla 2. Elementos por considerar para definir la Capacidad de Carga ambiental

Recursos renovables

- $\quad$ Reservas de aguas subterráneas.

- Árboles y vegetales diversos.

- $\quad$ Peces y otros animales.

Este concepto se refiere al rendimiento estable que se puede obtener, sin poner en peligro el futuro de cada recurso.

\section{Contaminación}

- Vertidos líquidos, sólidos y gaseosos en ríos, lagos, océanos y en la atmósfera.

La capacidad de carga se refiere a las cantidades de productos contaminantes que de estos se pueden absorber antes de ser alterados.
Para el caso de los bienes naturales, la tasa de utilización debiera ser equivalente a la tasa de recomposición del recurso. Para los recursos naturales limitados, la tasa de utilización debe equivaler a la tasa de sustitución del recurso en el proceso productivo, por el período de tiempo previsto para su agotamiento (medido por las reservas actuales y por la tasa de utilización). Si se toma en cuenta que su propio carácter de "no renovable" impide un uso indefinidamente sustentable, hay que limitar el ritmo de utilización del recurso, para la aparición de nuevos sustitutos. Esto requiere que las inversiones realizadas para la explotación de recursos naturales en general, a fin de ser sustentables, deben ser proporcionales a las inversiones asignadas para la búsqueda de sustitutos, como las inversiones en ciencia y tecnología (Guimarães, 1998).

\section{2- Dimensión social}

El origen de los problemas ambientales tiene una relación estrecha con los estilos de desarrollo de las sociedades industrializadas y las no industrializadas, por su cosmovisión del mundo, mediante perspectivas economicistas.

Fuente: Elaboración propia.

Mientras en las primeras, el sobreconsumo provoca insustentabilidad, puesto que la producción no va dirigida a satisfacer necesidades, sino a lucrar; en las segundas, es la pobreza-riqueza la causa primaria de la subutilización de los recursos naturales y ausencia de cobertura de las necesidades básicas que dan lugar a problemas como la deforestación, la contaminación o erosión de suelos, donde la explotación de estos recursos está, usualmente, en manos privadas o extranjeras.

Esta dimensión requiere que el desarrollo fortalezca la identidad y tradición de las comunidades, logre un equilibrio demográfico y la erradicación de la riqueza y pobreza. Se refiere a un acceso equitativo a los bienes ambientales, tanto intrageneracionales como intergeneracionales, entre géneros, como entre culturas (Boff, 1997). Esta dimensión permite apreciar la relevancia que adquiere la justa distribución de los bienes ambientales en un mundo donde la inequidad aumenta día con día (Martínez, 2012).

La sustentabilidad social implica promover un nuevo estilo de desarrollo que favorezca el acceso y uso de los bienes naturales y la preservación de la biodiversidad, el cual sea: 
Socialmente sustentable en la reducción de la pobreza y de las desigualdades sociales y promueva la justicia y la equidad; que sea culturalmente sustentable en la conservación del sistema de valores, prácticas y símbolos de identidad que, pese a su evolución y reactualización permanente, determinan la integración nacional a través de los tiempos; y que sea políticamente sustentable al profundizar la democracia y garantizar el acceso y la participación de todos en la toma de decisiones públicas. Este modelo tiene una nueva ética del desarrollo, en la cual los objetivos económicos del progreso estén subordinados a las leyes de funcionamiento de los sistemas naturales y a los criterios de respeto a la dignidad humana y de mejoría de la calidad de vida de las personas" (Guimarães, 1994).

Pero la sustentabilidad deberá promover cambios cualitativos en el bienestar de las sociedades y afianzar el equilibrio ambiental planetario, así como considerar la dimensión social en su más profundo sentido. Es decir, es natural que un ser humano en situación de extrema pobreza, exclusión, marginalidad (subconsumo) o en situaciones de riqueza (sobreconsumo), no pueda tener un compromiso estrecho con la sustentabilidad. Los fundamentos sociales de la sustentabilidad suponen postular como criterios básicos de política pública los de la justicia distributiva, para el caso de bienes y de servicios, y los de la universalización de cobertura, para las políticas globales de educación, salud, vivienda y seguridad social (Guimarães, 1998). Las condiciones para alcanzar un desarrollo sustentable requieren de acuerdos que incluya a los actores sociales, políticos y la agenda pública del Estado (Rodríguez y Govea, 2006; Milá, 2014).

Pero, es necesario plantear: ¿cuáles son los actores promotores del desarrollo sustentable?

Actualmente se convive con dos realidades contrapuestas. Por un lado, los actores sociales concuerdan en que el estilo de desarrollo actual se ha agotado y es insustentable, no sólo desde el punto de vista económico y ambiental, sino en lo que se refiere a la justicia social (Guimarães, 1998). Por el otro lado, no se adoptan las medidas requeridas para la transformación de las instituciones que dieron sustento al estilo de vida actual.

El concepto de sustentabilidad social supondría una regulación ambiental al proceso económico, sin afrontar todavía los procesos institucionales y políticos, reguladores de la propiedad, control, acceso y uso de los bienes naturales y servicios ambientales; en términos generales no conlleva a impedir uso de recursos, sino a que el uso de éstos cubra las necesidades sociales, sin excluir a ninguna comunidad.

La creciente importancia dada a los criterios de consumo y de producción sustentable es un objetivo que los países alcanzarán cuando comiencen a reconocer que la sustentabilidad demanda un enfoque estratégico a largo plazo, para transformar las causas de los problemas socioambientales (Duran y Lara, 2010). En relación con los patrones de consumo, es posible señalar que están determinados por los derechos básicos para la protección de los consumidores en el mundo:

- Satisfacción de necesidades básicas: acceso a productos y servicios básicos, como alimentos nutritivos, ropa, vivienda, servicios de salud, educación y sanidad.

- Seguridad: protección contra productos, procesos de producción y servicios que perjudiquen la salud o atentan contra la vida.

- Información: acceso a información necesaria para tomar decisiones informadas $y$ protegerse contra la publicidad o el etiquetado deshonesto o engañoso.

- Elección: poder elegir entre una gama de productos, ofrecidos a precios competitivos, con garantías de calidad satisfactoria.

- Representación: representar los intereses del consumidor en el diseño y ejecución de políticas estatales, así como el desarrollo de productos y servicios. 
- Reparación: recibir resolución equitativa por reclamos justificados, como la indemnización por productos de mala calidad o servicios insatisfactorios.

- Educación del consumidor: adquirir los conocimientos y habilidades necesarias para tomar decisiones informadas sobre productos y servicios; al mismo tiempo, estar consciente de los derechos y responsabilidades básicos del consumidor y cómo ejercerlos.

- Ambiente saludable y sustentable: vivir y trabajar en un ambiente que no amenace el bienestar de la población presente y futura.

\section{3- Dimensión económica}

Esta dimensión es de la que más espacios se ocupa en los medios de información, eso sí, desde una perspectiva meramente economicista de los intereses, en su mayoría, "corporatocráticos" (Dugin, 2012b). El debate economía - ambiente es uno de los que ha suscitado arduas polémicas en términos de su relación con la sustentabilidad. La ciencia económica convencional no tiene una respuesta convincente a la crítica ecológica, a pesar de que la ciencia del management ha planteado ciertos enfoques orientados a reconocer la importancia de la optimización del uso de los recursos (Pappas y Brigham, 1984), esta no deja de lado la lógica productivista y comercial, pero sí la replantea hacia enfoques más sustentables.

La economía clásica falla al valorar la riqueza global de las naciones, sus recursos naturales y en los precios de las materias primas, destaca la cuantificación económica de los recursos, ante estos enfoques Sandel (2013) cuestiona hasta qué punto los valores del mercado han sobrepasado los límites sociales, como: salud, medicina, educación, gobierno, ley, arte, deporte, incluso la vida familiar y las relaciones personales. Por ejemplo, sobre el precio de los recursos energéticos agotables, su valoración siempre es menor que la real en términos de su preservación para las futuras generaciones. También es posible cuestionarse si el precio que las industrias tienen que pagar por insertar residuos no reciclados al ambiente, tampoco sea el racional. Entonces, cuáles serán los precios adecuados. Aquí se debe incorporar la noción de "externalidades" como los aspectos ambientales sin valoración cuantitativa en la contabilidad o proceso de producción. De allí la importancia de valorizar los recursos, al menos por su costo de reposición, y construir con ellos cuentas del patrimonio natural para determinar qué y cuánto se tiene, cómo se podría usar en diferentes alternativas y cuánto queda en cada caso: principio básico de la ciencia del management mediante el ejercicio de la Planificación Estratégica.

Esta dimensión demanda un desarrollo económicamente eficiente y equitativo, por lo que exige redefinir la actividad económica de acuerdo con las necesidades materiales e inmateriales, entendidas no sólo como carencias, sino como potencialidades (Martínez, 2012). Las actividades económicas deben basarse en unidades de producción locales y diversificadas, adaptadas a las características de los ecosistemas para usarlos de manera sustentable. En la siguiente tabla se indican los aspectos que todo sistema económico debe solucionar, planteándolos para lograr una dimensión sustentable: 
Tabla 3. Aspectos que cada sistema económico debe resolver

\begin{tabular}{|c|c|c|c|}
\hline Problema & A qué responde & Elementos & $\begin{array}{l}\text { Aplicación dentro de la } \\
\text { dimensión de sustentabilidad }\end{array}$ \\
\hline $\begin{array}{l}\text { Eficiencia } \\
\text { Asignativa }\end{array}$ & ¿Qué producir? & $\begin{array}{l}\text { Tipos y cantidades de bienes y } \\
\text { servicios. } \\
\text { Modo de consumo según } \\
\text { satisfacción acorde con presupuesto. } \\
\text { Eficiencia en asignación de recursos. }\end{array}$ & $\begin{array}{l}\text { Investigación de operaciones: } \\
\text { modelado matemático, } \\
\text { heurísticas, modelos de } \\
\text { simulación. Definan, } \\
\text { científicamente, asignación } \\
\text { recursos, para evitar desperdicio. }\end{array}$ \\
\hline $\begin{array}{l}\text { Eficiencia } \\
\text { Productiva }\end{array}$ & ¿Cómo producir? & $\begin{array}{l}\text { Menor costo. } \\
\text { Menor cantidad de recursos, } \\
\text { orientada a minimizar impacto. }\end{array}$ & $\begin{array}{l}\text { Evitar el endeudamiento } \\
\text { (Salbuchi, 2012). } \\
\text { Utilizar solo lo que se requiere, } \\
\text { Estado que fiscalice uso de } \\
\text { recursos, mediante planificación } \\
\text { (Milá, 2014). } \\
\text { Producción local a pequeña } \\
\text { escala (Cañada y Gastón, 2007; } \\
\text { Cañada, 2013). }\end{array}$ \\
\hline $\begin{array}{l}\text { Eficiencia } \\
\text { Distributiva }\end{array}$ & ¿Para quién producir? & $\begin{array}{l}\text { Comunidades que consumen lo } \\
\text { producido. } \\
\text { Satisfacción por el consumo, } \\
\text { relación Costo/Beneficio. } \\
\text { Utilidad marginal = costo marginal. }\end{array}$ & $\begin{array}{l}\text { Evitar la masificación, entrega } \\
\text { del producto o servicio según } \\
\text { capacidad de carga, para evitar } \\
\text { sobrepasarla. }\end{array}$ \\
\hline
\end{tabular}

Fuente: Elaboración propia a partir de Meyer (2004).

Para desarrollar la dimensión económica de la sustentabilidad, se requiere un modelo económico regulador adecuado con los ciclos biogeoquímicos de la materia, y le permita perpetuarse en el tiempo. Existen acuerdos para establecer determinadas metas ambientales, así como normas que influirían en la mejora ambiental de una empresa, pero cuya aceptación y desarrollo son voluntarias (normas ISO 14000). Y también existen procedimientos de evaluación de los impactos ambientales generados por un proyecto o actividad (Valdés, 2006).

\section{4- Dimensión cultural}

La dimensión cultural es de las más afectadas por los procesos de globalización desarrollados por los modelos económicos capitalistas, de cortes liberales (Shamir, 2015; Petras, 2015; Savin, 2015). Debido a los contextos de crecimiento y desarrollo económico, liderados por naciones poderosas hacia otras regiones menos favorecidas, se impone por la fuerza u otros medios de control (Freytas, 2011a) una especie de "imperialismo cultural" (Petras, 2015), el cual desplaza la producción local para imponer mercancías, ideas, productos y servicios, para así lograr la acumulación de capital en beneficio de las multinacionales; la consecuencia de esto ha sido la imposición de un modelo "cultural" del que Sunic (2007) denomina: Homo americanus, una clara 
amenaza hacia las expresiones culturales autóctonas de las diversas regiones del mundo.

Es importante replantear la evolución de la sociedad hacia estilos de producción y consumo sustentables, lo cual implica un cambio en el modelo de civilización dominante en la actualidad, en particular a los patrones culturales de relación sociedad-naturaleza.

La comprensión de la crisis supone el reconocimiento de que ésta se refiere al agotamiento de un estilo de desarrollo ecológicamente depredador, socialmente perverso, políticamente injusto, culturalmente alienado y éticamente repulsivo. Lo que está en juego es la superación de los paradigmas de la modernidad que han estado definiendo la orientación del proceso de desarrollo. En ese sentido, la modernidad emergente es la 'modernidad de la sustentabilidad', en donde el ser humano vuelva a ser parte de la naturaleza (Guimarães, 1998).

La sustentabilidad debería promover la productividad de la base de los recursos y la integridad de los sistemas ecológicos, así también los patrones culturales y la diversidad cultural de los pueblos, lo que permitiría el florecimiento de colectivos identitarios, tradicionalistas y demás, los cuales preserven el patrimonio cultural heredado y eviten la disociación de la población local con sus raíces patrimoniales y tradiciones que pudiesen basarse en solidaridad, al sustituirlas por necesidades artificialmente creadas y comercializadas (Freytas, 2011b. Petras, 2015).

Actualmente, la principal causa de la insustentabilidad posee una dimensión cultural, según sea la cosmovisión o forma de ver el mundo y la forma de interactuar con este; sin embargo, si el patrimonio cultural se pierde, es posible una pérdida de elementos transmisores de la identidad social de una región (Ruiz de Aguirre, 2008). Desde esta perspectiva, la cultura occidental contemporánea, en su mayoría liberal, es insustentable, por lo que sus fundamentos deben ser replanteados (Dugin, 2013). Su relación con el entorno se basa en la idea de la cosificación y apropiación de la naturaleza como una inagotable fuente de recursos. Así, la sustentabilidad resulta clave para comprender las relaciones existentes entre los sistemas naturales y sociales, y para tener una percepción más clara de la importancia de los factores socioculturales en la génesis de los problemas ambientales, por eso debe impulsar la conciencia, los valores y los comportamientos favorecedores de la participación efectiva de la población local en el proceso de toma de decisiones.

La sustentabilidad implica una relación entre la sociedad-naturaleza, para resolver las injusticias sociales: miseria, riqueza, violencia; toma en cuenta la capacidad y planificación del espacio tierra: manejo sustentable de los ecosistemas. Para satisfacer necesidades reales, no artificiales inducidas.

La sustentabilidad cultural comprende la situación de equidad promotora de que los miembros de una comunidad o país accedan con igualdad a oportunidades de educación y aprendizaje de valores congruentes con un mundo crecientemente multipolar, multicultural y multilingüe y de una noción de respeto y solidaridad en términos de sus modos de vida y formas de relación con la naturaleza. Es deber de cada sociedad el respeto hacia las tradiciones de otras sin imposturas ni menosprecio.

\section{5- Dimensión educativa}

El concepto de dimensión sustentable en términos de educación es dinámico, se modifica a la par del medio ambiente, la ecología y también según la percepción de los distintos sujetos sociales y contextos. Tradicionalmente, se trabajaban los aspectos naturales del ambiente, desde planteamientos próximos a las ciencias naturales. Luego, surge la necesidad de incluir de forma explícita al ambiente en los procesos educativos, pero la atención se centró en cuestiones como la conservación de los bienes naturales, la protección de la fauna y flora y sus ciclos.

Actualmente, se reconoce que aunque los elementos físico-naturales constituyen el sustento del ambiente; también las dimensiones socioculturales, políticas y económicas son básicas para entender las relaciones establecidas con su entorno por la 
humanidad y para gestionar los ecosistemas en un contexto de sustentabilidad y su comprensión integral, por lo que se ha tomado conciencia de la interdependencia existente entre el ambiente, el desarrollo y la educación. Es esa conciencia la que conduce a reorientar la educación de modo que, además de la preocupación por el manejo sustentable de los recursos, florezca el interés por su reparto y se modifiquen los modelos de desarrollo para su utilización óptima, con la meta de evitar la degradación ambiental, sin responder a ningún tipo de interés externo, el cual pudiese ajustar datos para que calcen acorde con su ideología y beneficio propio, y utilizarlos como herramienta científica (conocimiento) para justificarse.

La dimensión educativa de la sustentabilidad es una respuesta transversal a toda la educación y que aporta un nuevo paradigma que brinda un profundo giro de innovación cultural (Martínez, 2012). La educación ambiental es un proceso de toma de conciencia y acción sociales sobre los problemas sociales, ambientales y sus alternativas de solución, de modo práctico y objetivo, sin ataduras ideológicas. Esta definición, socialmente reconocida por la población en general, por quienes participan activamente en pro del ambiente, por los profesionales, científicos expertos y por los educadores, revela una distancia notable entre el discurso, o lo que se manifiesta verbalmente y la acción, lo que se hace. La praxis -en la dimensión educativa- no coincide con las consignas consabidas porque no sería tan evidente el contraste entre los resultados económicos promisorios y los indicadores de pobreza y riqueza, raíz de los problemas ambientales.

El saber ambiental (Leff, 1998) es transdisciplinario y reúne un marco teórico de gran solidez. Este saber no es un ámbito nuevo del conocimiento o una nueva disciplina, sino un campo de conocimiento en el que convergen los aportes de conceptos y metodologías de diversas ciencias, las cuales tratan los sistemas ambientales complejos que funcionan como conjuntos de interacciones entre las distintas esferas de la Tierra y la sociedad.

\section{6- Dimensión geográfica}

La dimensión geográfica de la sustentabilidad tendrá diferentes interpretaciones para una aldea africana, una aglomeración latinoamericana o una nación industrializada europea; cada sociedad se desarrolla en un entorno específico y por medio de la globalización los contextos parecieran no ser tan específicos. Quizás, la sustentabilidad sea más relevante para un estado industrial por el deterioro ostensible, mientras la sustentabilidad no sea aún "consciente" para una aldea africana y, que ha sido practicada por las culturas precolombinas.

Las dimensión geográfica -también denominada territorial- de la sustentabilidad constituye uno de los principales desafíos de las políticas públicas contemporáneas -de ordenamiento y planificación ambiental y territorial-, que requiere territorializar la sustentabilidad ambiental y social del desarrollo y, a la vez, sustentabilizar el desarrollo de las regiones; es decir, garantizar que las actividades productivas de las distintas economías regionales promuevan la calidad de vida de la población local y protejan el patrimonio natural y cultural (Guimarães, 1998).

El modo de equilibrar el actual modelo de subdesarrollo insustentable (Di Pace et al., 1992) es mediante la inserción de la dimensión ambiental y de la dimensión geográfica en la política (geopolítica), aspectos poco relevantes en los países latinoamericanos en los que se difunde un discurso ambiental, pero no una verdadera política ambiental integral, es decir, un mero discurso, relativamente poco teorizado y escasamente practicado.

La dimensión geográfica de la sustentabilidad implica el progreso de los distintos sistemas espaciales-ambientales, atenúa las disparidades y distorsiones del territorio, además de promover sus potencialidades y limitar las vulnerabilidades. "El objetivo final de la ordenación territorial es lograr una relación sustentable entre el ambiente y los asentamientos humanos con el propósito de disminuir las desigualdades regionales y lograr un desarrollo socialmente equilibrado, respetando la naturaleza" (Duran y Lara, 2010). Lo que Duran y 
Lara (2010) indican lo manifiestan también Pappas y Brigham (1984) con su enfoque de producir a partir de lo que se tiene, sin desperdicios ni agotamiento de recursos, eso sí, desde una perspectiva más comercial, pero igualmente aplicable.

Para lograr ese objetivo es necesario que la relación sociedad-ambiente no se defina mediante generalizaciones macro, sino en una escala de relevancia inmediata o práctica de vida. Es la escala local y su integración regional, un principio de organización básica, que requiere autonomía de decisiones.

Ahora bien, la dimensión geográfica demanda que se aplique un ordenamiento territorial, como política estatal que incorpore la dimensión ambiental en la planificación del desarrollo, lo que implica el uso sustentable de los agroecosistemas y el respeto por la biodiversidad, como estrategia de conservación; ordenar la organización social, política e interinstitucional, la actividad productiva en general, para satisfacer las necesidades básicas de la población y regular la privada.

La defensa de los pueblos endógenos rurales contra las industrias extractoras, las grandes represas, la deforestación comercial o las plantaciones uniformes de árboles (con agrotóxicos y transgénicos) es parte de la defensa de la identidad de la tradición de los pueblos, contra métodos de dominación basados en extracción de recursos naturales, deuda y especulación financiera (Emry, 1982; Freytas, 2010; Salbuchi, 2012; Cañada, 2013; Soral, 2015). La semejanza estructural de muchos conflictos socioecológicos alrededor el mundo en culturas muy diferentes, teniendo en cuenta la dimensión geográfica de la sustentabilidad permite que los conflictos ecológico-distributivos no deban ser vistos como expresiones de la política de la identidad. La identidad étnica o social es uno de los lenguajes con que se representan los conflictos ecológico-distributivos, que nacen del uso cada vez mayor que la economía hace del ambiente natural del cual todas las naciones dependen para vivir, en detrimento de la dimensión geográfica de la sustentabilidad (Martinez-Alier, 2006).

\section{7- Dimensión política}

Se refiere a la participación directa de la población o personas en la toma de decisiones, en la definición de su futuro colectivo y en la gestión de los bienes socioculturales y ambientales, mediante estructuras de gobierno descentralizada y democrática. Plantea la necesidad de resignificar la política y generar nuevas prácticas basadas en la participación directa y el protagonismo de las personas y grupos de interés en general hacia la búsqueda de alternativas, que necesariamente deben surgir de relaciones horizontales, ajenas a esquemas centralizados y verticalistas que concentran el poder, como actores infra o suprapolíticos (Bourg, 2005), locales o externos. La sustentabilidad sólo será posible si se devuelve el poder de decisión al pueblo, su soberanía y autodeterminación económica, social, ambiental, cultural entre otras, lejos de los parámetros que amoldan el pensamiento liberal a escala planetaria (Dugin, 2012a; de Benoist, 2013; Soral, 2014).

La base política de la sustentabilidad está vinculada a los procesos de democratización y de construcción de la ciudadanía, y busca garantizar la incorporación plena de las personas a los beneficios de la sustentabilidad, esto sugiere que la sustentabilidad no es un fin, sino un medio para lograr un desarrollo equitativo, justo y soberano.

La sustentabilidad, en el nivel micro, en la democratización de la sociedad, supone el fortalecimiento de la capacidad de las organizaciones sociales y comunitarias, el acceso a la información de todos los ciudadanos en términos ambientales, sociales y económicos, así como una facultad y capacitación para la toma de decisiones. En el nivel macro, tiene que ver en la democratización del Estado fuerte y con capacidad para planificar, mediante el control ciudadano del Estado y la responsabilidad política en la actividad pública. Ambos procesos constituyen desafíos netamente políticos, los cuales solo podrán ser enfrentados a través de la construcción de alianzas entre diferentes grupos sociales, para proveer la base de sustentación y de consenso para el cambio de estilo de vida 
hacia la sustentabilidad. También requiere del replanteamiento de los organismos internacionales que tienen injerencia, a través de sus fondos para el desarrollo, cuestión de alta complejidad.

\section{Aplicaciones de las dimensiones de la sustentabilidad: respeto a las restricciones naturales}

Tras haber abordado las dimensiones de la sustentabilidad, se indica sus aplicaciones, al destacarse que el planeta Tierra tiene una capacidad restringida para generar bienes o recursos y para absorber la contaminación. La lógica del crecimiento continuo y exponencial, inherente al modelo económico desregulado, choca frontalmente con la realidad física de un planeta finito.

El conocimiento científico actual muestra aspectos como que el universo tiene límites, la vida solo se puede mantener dentro de ciertas condiciones, los seres vivos no crecen más allá de cierto tamaño bastante relacionado con el hábitat donde se desenvuelven (tierra, mar o aire) y la complejidad de los ecosistemas tiene su capacidad de carga natural, pues el aumento de las interrelaciones empieza a ser inmanejable, más exigente en gasto energético y a generar situaciones inestables.

Se observan restricciones por todas partes. Sin embargo, el modelo socioeconómico y productivo actual promueve una imposible superación de la escasez de recursos, bien sea porque no le interesa, o porque no comprende e ignora cómo replantear su enfoque. La escala de las actividades humanas ha superado las distintas adversidades que han garantizado la estabilidad de la vida en el planeta, por lo cual se agrava el papel, tanto de proveedor de recursos como con su capacidad para ser sumidero de residuos.

El desarrollo sustentable considera el conjunto de las actividades productivas, como el manejo de suelos y aguas, el manejo de cultivos y la conservación de la biodiversidad; y a su vez el suministro de alimentos y materias primas. La sustentabilidad de los sistemas de producción se refiere a la capacidad del sistema para mantener su productividad estable a pesar de las perturbaciones económicas y naturales, externas o internas. La sustentabilidad es función de las características naturales del sistema y las presiones e intervenciones que sufre; así como aquellas intervenciones sociales, económicas y técnicas que se hacen para contrarrestar presiones negativas; destacándose la resiliencia del sistema.

Al respecto, se plantean diez principios ecológicos para un desarrollo sustentable, donde seis principios conforman un grupo de prácticos (Toledo, 1995), entre estos se encuentran los siguientes:

$\checkmark$ Diversidad: biológica, genética, ecológica, paisajística, productiva. Afirma un rasgo inherente al modo tradicional de apropiación del agroecosistema y entra en conflicto con la tendencia homogenizante y especializadora del desarrollo neoliberal que predomina, principalmente a partir de la globalización mundialista (de Benoist, 2013; Soral, 2014; Savin, 2015).

$\checkmark$ Autosuficiencia: alimentaría, energética, tecnológica, económica. Supone la mínima dependencia de la comunidad rural de los insumos externos. No se debe confundir con la autarquía, que supone un aislamiento total.

$\checkmark \quad$ Integración: de prácticas productivas, de unidades de paisajes, de ciclos naturales. Está presente en la racionalidad ecológica y económica tradicional, ese principio se erosiona por la práctica dominante moderna y dependencia de las comunidades.

$\checkmark$ Equidad: productiva, de recursos, de participación, de toma de decisión y otras, frente a los mecanismos externos que promueven la diferenciación social y económica de las comunidades (con sus diversas formas de caciquismo). La equidad es un supuesto obligado de toda organización social comunitaria.

$\checkmark \quad$ Justicia: dirigido a obtener precios justos para los productos comercializados por la comunidad, este principio busca enfrentar los diferentes mecanismos del intercambio económico desigual, donde las comunidades han sido históricamente explotadas por los 
mercados externos, estos últimos aplican estrategias como la especulación financiera, generadora de burbujas y crisis.

$\checkmark$ Racionalidad: la aplicación del uso múltiple del agroecosistema permite y promueve la diversidad ecológica biológica, genética y el ciclo de los flujos de materia y energía del agroecosistema. Ello se logra mediante una distribución equitativa de las áreas dedicadas a la agricultura, ganadería y forestal en el territorio comunitario, contrario al monocultivo.

Y los otros cuatro principios, son filosóficos, se reconocen alrededor de la idea de equilibrio:

$\checkmark$ Equilibrio Espacial: dirigido a garantizar la estabilidad del paisaje, mediante un manejo sustentable de las diferentes unidades ecogeográficas que conforman el territorio comunitario y su integración en los procesos productivos.

$\checkmark$ Equilibrio Productivo: trata de mantener una estrategia donde el valor de cambio (producción para el mercado) esté siempre bajo el dominio de los intereses y necesidades de locales o valor de uso (producción dirigida a garantizar la autosuficiencia alimentaria, energética, tecnológica y otras de la comunidad).

$\checkmark$ Equilibrio Comunitario: busca equilibrar los intereses del todo y los intereses de sus partes (enfoque sistémico); es decir, entre los derechos e intereses colectivos o comunitarios y los derechos e intereses de las familias y personas que forman la comunidad. Trata de evitar los excesos del colectivismo y de aprovechar las ventajas y potencialidades de las personas.

$\checkmark \quad$ Equilibrio Familiar: las familias son células productivas y sociales de toda comunidad, resulta de enorme importancia garantizarle una cierta estabilidad. Este principio busca respeto entre las personas, sexos y generaciones, para garantizar la satisfacción de sus necesidades esenciales, mediante normas adecuadas de salud, alimentación, higiene, educación, reproducción, información y recreación.

\section{Propuestas prácticas para alcanzar la sustentabilidad}

Sólo un desarrollo y producción social y ecológicamente sustentable puede realizar los objetivos políticos y sociales del Estado, en forma integral y universal (Altieri, 1999). Esto conduce a los retos que deberá abordar toda política que pretenda defender el nuevo papel del Estado:

$\checkmark \quad$ Los ciclos económico-productivos han de ser circulares e integrados a los ciclos ecológicos (coordinados), partiendo de la naturaleza finita de los recursos. Hay que aplicar el decrecimiento y universalizar el desarrollo, mediante un nuevo paradigma. Producir para cubrir necesidades colectivas humanas y no intereses privados ni corporativos, aunque se pueden regular. Con énfasis en los intereses colectivos, sobre los privados, pero con respeto de ambos.

$\checkmark$ Implica un esfuerzo de producción y desarrollo sobre una tecnología dirigida hacia la eficiencia (relación insumos y productos / servicios finales) y la eficacia (relación entre objetivos / resultados), lo cual permita una considerable reducción energética. La calidad de un sistema productivo no está por la cantidad de energía y materias consumidas; sino por el reciclaje eficiente y el uso óptimo de los recursos (sin desperdicios ni sobreproducción).

$\checkmark$ Reconoce límites o restricciones, para aplicar una regulación al crecimiento productivo insustentable, propiedad privada en términos de recursos estratégicos y desarrollo social, explotación irracional del ecosistema, eliminar todo tipo de injusticias sociales: violencia, miseria, riqueza, privatización.

$\checkmark \quad$ El desarrollo desigual e injusto existe en el plano socioeconómico y ecológico, como un agravante de los impactos socioambientales; estimular nuevos valores, actitudes y comportamientos ecocéntricos hacia el entorno socionatural. 
$\checkmark \quad$ La energía renovable es la opción tecnológica para superar las políticas mercantiles, vinculadas a las fuentes exosomáticas no renovables, por lo que se deben de subsidiar; aplicación de las 4 erres: reducir, rechazar, reciclar y reutilizar.

$\checkmark$ Aplicar un nuevo ordenamiento territorial socioambiental, mediante la relación estrecha de Capacidad de uso de la tierra = Planificación del uso de la tierra: uso sustentable del agroecosistema; aseguramiento de la producción autoalimentaría, para eliminar la pobreza y hambre y redistribuir justamente la riqueza.

$\checkmark \quad$ Descentralizar el poder hacia las comunidades locales, para que las tomas de decisión y solución sean democráticas, colectivas y participativas; rescatar y reconstruir lazos sociales que permitan la satisfacción y que no depredan el medio o explotación social. Son necesarios, los valores y elementos culturales que refuerzan los sentimiento de solidaridad y "disfrute espiritual".

Un modelo de desarrollo sustentable real requiere proteger la sociedad, su patrimonio cultural, tradición e identidad nacional, así como los ecosistemas y sus diversas especies de flora y fauna, que juegan un papel esencial en el mantenimiento de los procesos ecológicos y socioeconómicos; lo cual implica:

$\checkmark$ Ruptura de las formas de dependencias, especialmente de los mercados internacionales y al interés del dinero (Emry, 1982; El Diwany, 2003; Soral, 2014).

$\checkmark \quad$ Uso del agroecosistema que respete que sus ciclos de materiales y energía, sean cerrados.

$\checkmark$ Manejo de los impactos benéficos.

$\checkmark$ Uso y funcionamiento del agroecosistema, con tolerancia de condiciones biofísicas adversas, que favorecen tanto a humanos y la naturaleza.

$\checkmark$ Mecanismos bióticos de regeneración de los materiales deteriorados. $\checkmark$ Valoración, regeneración y/o creación de conocimientos locales, que mejoren el nivel de vida de la población, desde su propia identidad local.

$\checkmark \quad$ Establecimiento de circuitos cortos para el consumo de mercancía, para reducir costos.

$\checkmark$ Potenciación de la biodiversidad biológica y sociocultural, especialmente en la industria turística, la cual es la que más explota estos recursos y, por ende, debe ser líder en su conservación.

$\checkmark \quad$ Distribución justa de la riqueza social y del agroecosistema.

$\checkmark$ Relaciones de respeto entre las áreas: urbanorural.

Se trata de una nueva perspectiva, pues a pesar de que existe consenso en los foros internacionales sobre la importancia y dimensiones de este concepto; la realidad es que su aplicación en distintas escalas geográficas, especialmente en las escalas nacional, regional y local, es todavía muy incipiente e ineficiente. Además, existe una subvaloración de la dimensión territorial que trae efectos muy negativos en la planificación sustentable. Se debe considerar la sustentabilidad desde una perspectiva geográfica, cultural, política, axiológica y educativa para completar el carácter complejo que abarca este concepto.

Por otro lado, es preciso comprender que el modelo agroindustrial convencional se agota, no es la solución, como pretenden los gobiernos (de políticos y empresarios), sino, que es la causa de los problemas socioambientales actuales. Sin embargo, para generar un proceso de desarrollo sustentable es necesario cuestionar el desarrollo y sistema de dominación convencional (Freytas, 2010) (instituciones, leyes), que como modelo está en franca decadencia e implantar uno que replantee las estructuras locales, nacionales e internacionales, más acorde con la realidad, contextos y necesidad de los tiempos, el cual respete los ciclos ecológicos y el devenir sociocultural de las diversas naciones, con respecto a esto se plantea la Ilustración 5, donde indica los deberes de los diversos actores para replantear el modelo convencional hacia uno sustentable. 


\section{Ilustración 3. Modelo de las 3C de la Sustentabilidad}

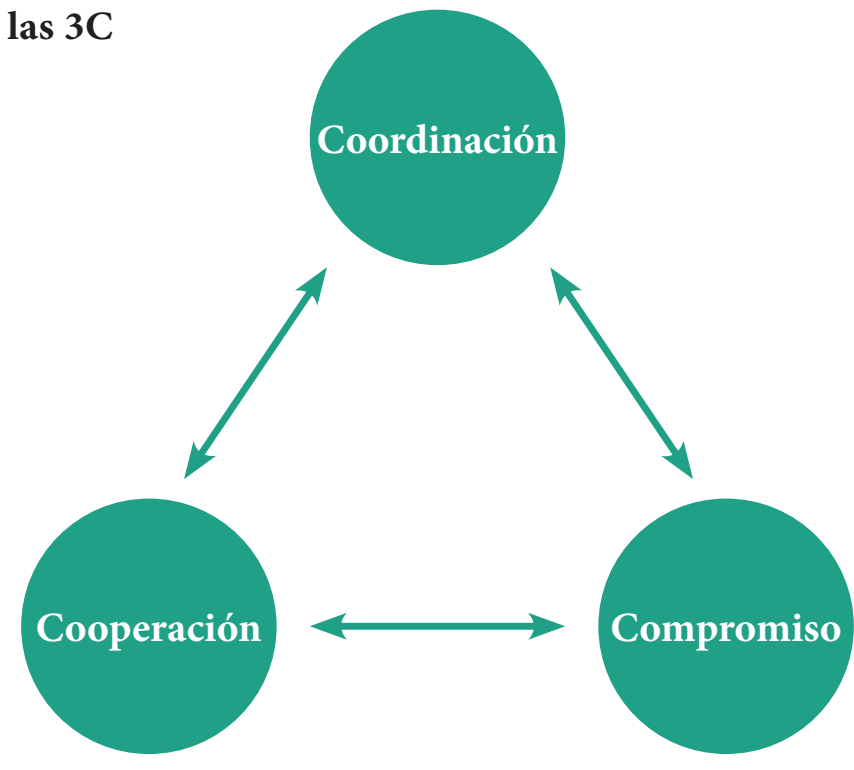

Fuente: Elaboración propia.

Una breve explicación de la Ilustración 5 indica que los diversos actores sociales deben:

- Coordinar sus esfuerzos para alcanzar metas óptimas: interés social por encima del individualismo, para evitar la corrupción (Venner, 2013).

- Cooperar para que el resultado sea equitativo y justo.

- Comprometerse a continuar con un enfoque que garantice la sustentabilidad.

Por lo tanto, cualquier propuesta en torno al desarrollo sustentable debe basarse en la pluralidad de los actores involucrados, sus necesidades e intereses, y a su vez, es preciso señalar sus responsabilidades en un marco de principios sociales equitativos, por encima de intereses individualistas de origen exclusivamente financiero-económicos ("deudocracia, corporatocracia").

\section{Conclusión}

Los problemas económicos, sociales y ecológicos nos son coyunturales, sino estructurales y para salir de este atolladero hará falta una gran transformación en los valores, prioridades y necesidades, esto permite una mayor pluralidad teórico metodológica para alcanzar el desarrollo sustentable, preservar los valores de cada sociedad y su papel en la historia. Para ello, los seres humanos están obligados a mantener estable el ecosistema planetario, en un acto de solidaridad con su entorno; puesto que forma parte de una inmensa comunidad cósmica y planetaria. Donde, todos son interdependientes, y comparten el mismo destino (Boff, 1996).

Los obstáculos que enfrentados por la sustentabilidad son básicamente teórico metodológicos: deficiencias de las ciencias sociales frente a lo ambiental (clima, vegetación, producción, reforestación; deficiencia de la ciencia social frente a lo social (aspectos de la economía, riqueza, pobreza), y deficiencia frente a lo político (planes y modelos de desarrollo, estructuras administrativas gubernamentales caóticas). Además, existe un agotamiento político ideológico del liberalismo y marxismo, (Dugin, 2012a), por lo que son necesarios aportes más holísticos y transversales para el diagnóstico y análisis, para comprender el mundo actual (globalización, post-modernidad, geopolítica, atomismo), mediante planteamientos que responden a los nuevos contextos (antiliberalismo, tradición e identidad, multipolaridad, desarrollo sustentable).

Alcanzar el desarrollo sustentable es uno de los grandes retos del nuevo siglo y no meramente una opción, pues el desarrollo insustentable no es resultado de una mala planificación o ejecución de un proyecto, ni falta de visión o desestructuración 
institucional. La crisis socio-ambiental no es tampoco un problema técnico, ni tecnológico, ni económico, ni social, ni cultural; es ético, es moral, es humanista, pero sobretodo es político (sistema capitalista y su ideología neoliberal), con sus estructuras de relaciones deshumanizadas y desnaturalizadas (socio-político), que enfatizan en mercados desregulados, donde el reajuste de la economía nacional y los sacrificios internos no se comparten de modo equitativo, ni se toman en cuenta las necesidades locales de los grupos más indefensos, para regular la concentración de riqueza, eliminar la pobreza y el hambre debidamente. Se debe cambiar el énfasis de maximizar la producción y el consumo para resolver sus intereses externos, en detrimento de las necesidades y responsabilidades socioeconómicas y ambientales locales, nacionales.

Ha llegado el momento de que los que estén preocupados por el destino de la Tierra enfrenten los hechos: no solo la grave realidad de la gran degradación ambiental y escasez de recursos, sino también la acuciante necesidad de un cambio en el sistema social, económico y político. Se está entrando en un proceso que obliga a repensar todo: política, economía, cultura, diplomacia, educación, estilos de vida, naturaleza, ideas e ideologías, modelos de negocios; por eso se necesitará construir una alternativa, fuera del paradigma de la modernidad liberal (Dugin, 2012a, 2013, 2014; de Benoist, 2013) y de su construcción de ideas universales estandarizadas del "homo americanus" (Sunic, 2007). Es necesario replantear un cambio de percibir, pensar y actuar en las interrelaciones del ecosistema, pero que debe de ser transversal y transdisciplinario (Martínez, 2005).

Estos cambios deben de conducir a una relación socioeconómica y ambiental más justa y equitativa, y asumir un desarrollo sustentable basado en los principios de equidad social, respeto a la integridad ecológica de los ecosistemas, modelo económico alternativo y desarrollo más participativo. Se trata de tomar partido por una opción viable para el futuro de los seres humanos y de la naturaleza. La concepción sustentable y su relación con su entorno es fundamentalmente una opción de vida, una opción humana que, solo como alternativa de desarrollo sustentable, la puede proporcionar realmente; donde otro sistema económico no solo es posible sino necesario.

\section{Bibliografía:}

Altieri, M. (1999) Agroecología: bases científicas para una agricultura sustentable, Ed. Nordan-Comunidad, Uruguay.

Baquiast, Jean-Paul 11/06/2010. A l'heure des compétitions mondiales entre corporatocraties anthropotechniques ( http://www.admiroutes.asso.fr/ larevue/2010/107/cat.htm

Beck, U. (1998) La sociedad de riesgos: hacia una nueva modernidad. Barcelona, Paidos.

Benoist, A (2013). Crítica de la ideología liberal. Página Transversal. Recuperado de: https://paginatransversal.wordpress. com/2013/12/13/critica-de-la-ideologialiberal/

Beveraggi, W. (1982). Teoría cualitativa de la moneda: contra el monetarismo, la inflación y el paro. Ed.Fuerza Nueva.

Bifani, P. (1997) Medio Ambiente y Desarrollo. Universidad de Guadalajara. México. 699p.

Bochaca, J. (2007). El enigma capitalista. Editorial Ojeda, $5^{a}$ edición.

Boff, L. (1996) Ecología: grito de la tierra. Grito de los pobres. Ed. Trotta, España.

Bourg, D (2005) ¿Cuál es el futuro del desarrollo sostenible?. Ediciones Akal. Madrid.

Brundtland, G.H. (1988) Our common Future (Oxford, Oxford University Press.

Cañada, E. (2013). Turismos en Centroamérica: un diagnóstico para el debate. Editorial Enlace, Managua. 
Cañada, E. y Gastón, J. (2007). El turismo y sus mitos. 1a ed. - Managua : Enlace

Collado, A (2012) Desertificación en Argentina: el problema de las 60 millones de hectáreas. Instituto Nacional de Tecnología Agropecuaria. Recuperado: http://inta.gob. ar/noticias/desertificacion-en-argentina-elproblema-de-las-60-millones-de-hectareas/

Declaración de Estocolmo sobre el medio ambiente humano (1972). Recuperado dehttp://www.cedhj.org.mx/cedhj/legal/ declaraciones/decla11.pdf

Di Pace, et al. (1992) Las utopías del medio ambiente. Buenos Aires. Centro Editor de América Latina.

Dugin, A (2012a) The Fourth Political Theory. London: Arktos Media.

Dugin, A (2012b) El financiarismo: estadio supremo del capitalismo. The Fourth Political Theory -beyond left and right but against the center. Recuperado de: http://www.4pt.su/es/ content/el-financiarismo-estadio-supremodel-capitalismo

Dugin, A (2013). El Occidente actual debe ser aniquilado y la humanidad debe ser reconstruida en un terreno diferente. The Fourth Political Theory - beyond left and right but against the center. Recuperado de: http://www.4pt.su/es/content/el-occidenteactual-debe-ser-aniquilado-y-la-humanidaddebe-ser-reconstruida-en-un-terreno

Dugin, A (2014). Contra el mundo posmoderno. The Fourth Political Theory - beyond left and right but against the center. Recuperado: http://www.4pt.su/es/content/contra-elmundo-posmoderno.

Dunne, S (2014). La crisis del mar Aral. Revista Dunitar.
Dunne, S (2015). El verdadero desarrollo sostenible. Rebelión. Recuperado: http:// rebelion.org/noticia.php?id=195740

Duran, D. Lara, A. (2010) Convivir en la Tierra. Fundación Educambiente. Buenos Aires. Lugar Editorial.

Durán, D (2010) Las dimensiones de la sustentabilidad. Recuperado de http:// www.ecoportal.net/Temas_Especiales/ Desarrollo-Sustentable/las_dimensiones_de_ la_sustentabilidad

Emry, S (1982). Billions for the Bankers - Debt for the Peolple. Editorial Lord's Convenent Church, America's Promise Broadcast.

Fernández, R. (2009) El antropoceno: la crisis ecológica se hace mundial. Ecologistas en Acción, España.

Freytas, M (2010). Los condenados del mercado y las claves del estallido social. Rebelión. Recuperado de: http://www.rebelion.org/ noticia.php?id=109207

Freytas, M (2011a). Capitalismo: Una empresa de ladrones comunes disfrazada de “civilización”. Asamblea de Majaras. Recuperado de: http://asambleademajaras. com/articulos/detalle_articulo.php?id_ articulo $=868$

Freytas, M (2011b). Transnacionales y agronegocios: Peligro de una nueva catástrofe alimentaria mundial. Rebelión. Recuperado de: http://www.rebelion.org/ noticia.php?id=125671

Funtowicz S. y Ravetz J. (1994) Epistemología Política. Ciencia con la gente. Ed. AL, Buenos Aires.

Guimarães, R. (1998) La ética de la sustentabilidad y la formulación de políticas de desarrollo. Campinas, Brasil. Ambiente \& Sociedade, $\mathrm{N}^{\circ}$ 2, 1998 primer semestre, 5-24. 
Guimarães, R. (1994) El desarrollo sustentable: ¿propuesta alternativa o retórica neoliberal?. (Revista EURE, Vol. XX, n. 61.)

Hernández, A. et al. (2009) Guia Ecosocial. La crisis ecosocial en clave educativa. Guía didáctica para una nueva cultura de paz. CIP-Ecosocial, España.

Leff, Enrique (1998) Saber ambiental: sustentabilidad, racionalidad, complejidad, poder. Editores Siglo XXI, S,A de C.V. México. $285 \mathrm{p}$.

Mackey, Jy Sisodia, R (2013). Conscious Capitalism: Liberating the Heroic Spirit of Business. Harvard Business Review Press; 1era Edición.

Martín, G (2012). Introducción al conocimiento y prevención de los contaminantes orgánicos persistentes. Ministerio de Agricultura, Alimentación y Medio Ambiente, Gobierno de España. V.A Impresores.

Martínez, R. (2005) Alternativa para un desarrollo sustentable. Revista Intersedes \#9, UCR. Martinez-Alier, J. (2006) Los conflictos ecológico-distributivos y los indicadores de sustentabilidad. Polis. Revista Universidad Bolivariana. Año Vol.5. No 3. Santiago de Chile.

Manifiesto para la Sustentabilidad, Simposio sobre Ética y Desarrollo Sustentable, Bogotá, Colombia, 2-4 mayo 2002.

Meadows, D.H. y D.L. (1991) Beyond the Limits. (traducción castellana de El País \& Aguilar, Madrid, 1992).

Meyer, D. (2004). Economía turística en América Latina y el Caribe. (1st ed.). Bogotá: Universidad Externado de Colombia.

Milá, E (2012). Teoría del mundo cúbico: Riesgos y destino de la globalización. Editorial EMINVES. Colección Actualidad Internacional.
Milá, E (2014). ¿Ha dicho “liberalismo"? Vamos a recordar qué es eso del liberalismo. InfoKrisis. Recuperado de: http://infokrisis.blogspot.com.es/2014/10/ha-dicholiberalismo-vamos-recordar-que.html\#more

M’Mwereria, G.K. (1996) Technology, Sustainable Development and Imbalance: A southern Perspective. (International Conference on Technology, Sustainable Developmente and Imbalance, Tarrasa, Spain).

Naredo, J.M. (1996) La economía en evolución. Historia y perspectivas de las categorías básicas del pensamiento económico. (Madrid, Siglo XXI).

Norgaard, R.B. (1996) Globalization and unsustainability. (International Conference on Technology, Sustainable Development and Imbalance, Tarrasa, Spain).

Onaindia, M. (2007). Sostenibilidad ecológica. Forum de Sostenibilidad, Cátedra UNESCO, 1:39-49.

Rodríguez, Isabel y Govea, Héctor (2006) El discurso del desarrollo sustentable en América Latina. Revista Venezolana de Economía y Ciencias Sociales., vol.12, no.2.

Pappas, J. y Brigham, E. (1984). Fundamentos de economía y administración. Interamericana de Ediciones, México.

Petras, J (2015). Imperialismo cultural. Página Transversal. Recuperado de: https://paginatransversal.wordpress. com/2015/03/03/imperialismo-cultural/

Ploeg, Jan D. van der (2000) Revitalising agriculture: farming economicalle as starting ground for rural developmente. Sociología Ruralis 40, pp.497-511. 
PNUMA (2014). Informe recuperación de la Capa de Ozono. Información recuperada de http://www.un.org/spanish/News/story. asp?NewsID=30409\#.VQyjDOFRI61

Polanyi, K. (1944). La gran transformación. Beacon Press, Boston, Massachusetts

Sachs, J. (2012) El precio de una civilización. Galaxia Gutemberg.

Sack, A. (1927). Los efectos de las transformaciones estatales sobre sus deudas públicas y otras obligaciones financieras: tratado jurídico y financiero. Recueil Sirey, Paris.

Salbuchi, A (2012). El “Modelo Shylock” de Deuda Pública. RT Actualidad. Recuperado de: http://actualidad.rt.com/opinion/salbuchi/ view/52913-El-Modelo-Shylock-de-DeudaP\%C3\%BAblica

Sandel, M (2013). Lo que el dinero no puede comprar - Los límites morales del mercado. Ed. Debate,Colección Actualidad Internacional.

Savin, L (2015). El lado oscuro de la Globalización. Página Transversal. Recuperado de: https://paginatransversal.wordpress. com/2015/02/20/el-lado-oscuro-de-laglobalizacion/

Shamir, I (2015). La tiranía del liberalismo. Página Transversal. Recuperado de: https://paginatransversal.wordpress. com/2015/03/03/la-tirania-del-liberalismo/

Solow, R. (1992) An almost Practical Step towards Sustainability. (Conferencia del 40 aniversario de Resources for the Future, 8-101991.)
Soral, A. (2014). Lo políticamente incorrecto como ideología de resistencia al Mundialismo. Página Transversal. Recuperado de: https://paginatransversal.wordpress. com/2014/10/31/lo-politicamenteincorrecto-como-ideologia-de-resistenciaal-mundialismo/

Soral, A. (2015). El fraude de la Deuda Privada. Página Transversal. Recuperado de: https://paginatransversal.wordpress. com/2015/01/30/el-fraude-de-la-deudaprivada/

Stern, N. (2007) El informe Stern: la verdad sobre el cambio climático, Paidós, Barcelona.

Sunic, T (2007). Homo americanus: Child of the Postmodern Age. Ed BookSurge Publishing.

Toledo, V.M. (1995) Campesinidad, agroindustrialidad, sostenibilidad: los fundamentos ecológicos e históricos del desarrollo rural. Cuadernos de Trabajo 3:1-45, 1995. Grupo Interamericano para el Desarrollo sostenible de la agricultura de los Recursos Naturales, México.

UNIÓN INTERNACIONAL PARA LA CONSERVACIÓN (1980) Estrategia Mundial para la Conservación: La Conservación de los recursos vivos para el logro de un desarrollo sostenido. Gland. UICN. Programa de las Naciones Unidas para el Medio Ambiente y el Fondo Mundial para la Naturaleza.

Valdés, J. (2006). ¿Es posible la sostenibilidad ambiental con la economía de mercado? Recuperado de www.rebelion.org/ noticias/2004/10/6111.pdf

Venner, D. (2013). El individualismo: origen último de la corrupción. Página Transversal. Recuperado de: https://paginatransversal. wordpress.com/2013/04/26/el-individualismoorigen-ultimo-de-la-corrupcion/ 